\title{
Perception of HIV among pregnant women in the public health system in two municipalities of the state of São Paulo
}

\author{
Cléa Adas Saliba Garbin ${ }^{1}$, Karina Tonini dos Santos Pacheco ${ }^{2}$, Thaís Fonseca Santiago ${ }^{3}$, Simone Miyada ${ }^{1}$, \\ Artênio José Ísper Garbin ${ }^{1}$, Suzely Adas Saliba Moimaz ${ }^{1}$
}

${ }^{1}$ Universidade Estadual Paulista - UNESP, Araçatuba Dental School, Department of Pediatric and Social Dentistry, Araçatuba, SP, Brazil ${ }^{2}$ Universidade Federal do Espírito Santo - UFES, Centro de Ciências da Saúde, Departament of Dentistry, Area of Dental Clinic, Vitória, ES, Brazil

${ }^{3}$ Dental surgeon - Caraguatatuba, SP, Brasil

\begin{abstract}
Aim: To verify the knowledge of pregnant women on mother-to-child transmission (MTCT) of HIV, the availability of HIV tests in the public health system and counseling on the disease in two cities, Birigui and Piacatu, São Paulo State, Brazil. Methods: This is a descriptive and exploratory research using as samples, the files of 141 pregnant women attending the Basic Health Unit. Data were collected by survey, followed by a semi-structured questionnaire with open and closedend questions. Data were analyzed on Epi Info ${ }^{\mathrm{TM}}$ 7.1.4, by the Chi-square and Exact Fisher tests. Results: From all the 141 pregnant women, 119 were interviewed and $92.4 \%$ reported to have been informed about the need of taking the HIV test during prenatal exams. However, only $5.9 \%$ were counseled and $20.2 \%$ reported to be aware of how to prevent MTCT of HIV, usually mentioning lactation suppression and prescribed medication. The association between the knowledge about how to prevent MTCT of HIV and some social, demographic and economic variables like ethnics, educational level, home location, occupation, age and parenting was not verified. Conclusions: It is necessary to advise pregnant women on the importance of taking the HIV test regardless of the examination outcome, which was not observed in the cities where the research was conducted.
\end{abstract}

Keywords: maternal and child health; HIV; public health.

\section{Introduction}

The prevalence of HIV among parturient women in Brazil is approximately 12,000 cases a year, and the detection rate has presented a significant statistical

Received for publication: October 30, 2015 Accepted: December 12, 2015

Correspondence to: Cléa Adas Saliba Garbin Departmento de Odontologia Infantil e Social Faculdade de Odontologia - UNESP

Rua José Bonifácio, 1193

CEP: 16015-050 Araçatuba, SP, Brasil Phone: +55 1836363249 Fax: +55 1836363332 E-mail: cgarbin@foa.unesp.br raise in the past 10 years ${ }^{1}$. This result has reflected the adaptation of prenatal care health policy with the aid of HIV vaccines ${ }^{2}$.

The HIV tests made during pregnancy guarantee the care and treatment for women and their children ${ }^{3}$. The Health Ministry advises both the HIV tests and counseling during pregnancy at the first prenatal visit and, whenever possible, the reapplication of vaccines at the beginning of the third trimester. Several guidelines have been established by the Health Ministry to direct how counseling should be conducted before and after the HIV test ${ }^{2}$. Counseling is a practice that allows both reflection and decision making. It is based on active listening, by which the health professionals seek to establish trust bonds, providing strategies 
that facilitate the recognition of users as participants in their own health condition ${ }^{4}$.

Knowledge of possible ways of HIV transmission from the mother to the infant is the most successful means of prevention ${ }^{5}$. However, researches report that social and demographical variables, such as educational level, age, urban life and the fact that these women are housewives or not, affect the mothers' knowledge about transmission ${ }^{6-9}$.

The purpose of this study was to verify the knowledge of pregnant women about MTCT transmission of HIV, availability of HIV tests in the public health system and counseling on the disease.

\section{Material and methods}

The present study is a descriptive exploratory research, approved by Ethics Committee of Araçatuba Dental School, UNESP, Brazil (process number FOA 2007-01422). Two cities in the state of São Paulo participated in the study, Birigui and Piacatu.

The records on all pregnant women from the Basic Health Units were used to determine the sample, according to their medical records and appointments, accounting to 141 pregnant women. The data were collected from patients scheduled to a gynecological visit at the Health Unit. The sample group was interviewed at the Basic Health Unit, whereas the patients who were not programmed timely were called and an interview with the pregnant women was scheduled at their homes.

The subjects were given explanations on the study objectives, and those who agreed to participate had their identities protected for ethical reasons. A pilot study was carried out in order to validate the research instrument and standardize the investigators.

Data were collected through a series of interviews, following semi-structured directions with open and closedend questions, designed especially for research purposes. The proposed questions comprised social, economical and demographic features, as well as knowledge about HIV prevention, MTCT of HIV, HIV testing and also the subsequent counseling.

The collected data were analyzed on Epi Info ${ }^{\mathrm{TM}}$ 7.1.4. The Chi-square using the Yates correction and Exact Fisher tests were used in order to verify the association between the patients' knowledge about MTCT of HIV and some social and economic variables, such as: ethnics, educational level, home location, occupation, age and parenting.

\section{Results}

Among the 141 pregnant women, 119 (84.4\%) agreed to take part in the study. The age of the population under study varied from 14 to 41 years old (mean age of 24.7 years old) and $48.7 \%$ were brown-skinned. Concerning the educational level, the majority $(60.5 \%)$ completed high school and only $8(6.7 \%)$ completed higher education.
Regarding the home location, the majority (96.6\%) reported to live in urban areas. As for their occupations, 52.29\% were housewives and $48.7 \%$ were primigravidae (Table 1).

The pregnant women who reported to have information on how to prevent HIV (89.1\%) indicated the television, school and health units as main sources of information; the relatives were less frequently indicated as sources of information.

Table 1 - Numeric distribution and percentage of social, economical and demographical variables.

\begin{tabular}{lc}
\hline Variables & Characteristics \\
Color & $\mathbf{n}(\%)$ \\
Caucasian & $47(39.5)$ \\
Black & $14(11.8)$ \\
Brown & $58(48.7)$ \\
Level of education & \\
Illiterate & $1(0.8)$ \\
Elementary school & $38(32.0)$ \\
High School & $72(60.5)$ \\
Superior & $8(6.7)$ \\
Area of residence & \\
Rural & $4(3.4)$ \\
Urban & $115(96.6)$ \\
Occupation & \\
Employed & $56(47.1)$ \\
Unemployed & $63(52.9)$ \\
Age* & \\
Young & $91(76.5)$ \\
Adult & $28(23.5)$ \\
Number of children & \\
Primigravidae & \\
Non-primigravidae & $58(48.7)$ \\
\hline
\end{tabular}

*Young: 14-29 years old; Adult: 30-49 years old

The majority of pregnant women (92.4\%) were informed about the need of taking the anti-HIV test during prenatal and $94.1 \%$ took the test. However, during the prenatal, $69.6 \%$ took the test only once and when questioned about counseling, only 7 women $(5.9 \%)$ answered positively.

Only $20.2 \%$ out of the sample reported knowing how to prevent MTCT of HIV and they mentioned only one method to avoid it. The most frequent answers were "not to breastfeed the baby" and "take medication" (Table 2).

The statistics showed a 0.0123 significance in the association between "HIV/AIDS awareness" and "level of education", as well as "age" $(p<0.0001)$. No association was verified among "realization of the tests", "counseling" and "prevention of MTCT" to the social, demographical and economical variables, such as ethnicity, level of education, home location, occupation and number of children" (Table 3).

\section{Discussion}

The profiles of the interviewed women match the ones found in the literature references ${ }^{10-13}$. It exposes a set of 
Table 2 - Percentage and absolute frequency distribution of the categories referring to the positive answers about the awareness of prevention of MTCT of HIV.

\begin{tabular}{lcc}
\hline Categories & Frequency \\
\hline & 14 & $\%$ \\
Lactation suppression- "The mother must not breastfeed". & 58.3 \\
Medication- "The doctor prescribes a medication to avoid & 6 & \\
transmitting HIV to the baby" & 3 & 25.0 \\
Labor - "Health cares to the umbilical cord". & 24 & 12.5 \\
\hline Total & & 100 \\
\hline
\end{tabular}

characteristics which fit in the pattern of favorable situations to the infection by HIV/AIDS, such as low level of instruction, customs, imposed sexual guidelines to women, lack of economical opportunities, lack of control over the relationships as well as gender vulnerabilities ${ }^{14}$.

Propagation of the knowledge on HIV/AIDS has arisen a conscious and preventive attitude in the population, especially regarding the conduction of the HIV tests, which cooperates to control dissemination of the disease and to the improvement of the population's health conditions. It was also verified all the pregnant women were doing prenatal visits, since their recruiting was through the Basic Health Unit, according to Veloso et al. ${ }^{15}$ (2010). Moreover, most of them took the HIV test, which strengthens other literature references ${ }^{11}$, setting its availability in the public health service.

In a previous study ${ }^{16}$, although the majority of interviewed pregnant women $(89.1 \%)$ reported to have received information on how to prevent HIV, there was little specific knowledge of transmission from mother to child, since $79.8 \%$ did not know how to prevent transmission. These results differ from those of Byamugisha et al. ${ }^{10}$ (2010), who reported that the majority of the interviewees were aware of the risks of HIV transmission and the ways to prevent contamination, accomplishing a successful outcome of a strong policy of counseling, monitoring, treatment and conduction of the HIV test. The low levels of knowledge about MTCT of HIV may be explained by lack of necessary information and counseling.

It is acknowledged that the pregnant women's serological status, availability of information and counseling are contributing factors to reduce the MTCT of HIV ${ }^{17}$. It must be stressed that the availability of information and advice is essential, so that there will be knowledge of the risks and means of prevention.

Filippi et al. ${ }^{18}$ (2006) showed that education is strongly associated with health. The perception of health problems and the ability to understand information on health problems, adoption of healthy lifestyles, use of health services, as well

Table 3 - Numeric and percentage distribution of positive answers given by pregnant women about information on HIV/AIDS, conduction of tests and counseling and prevention of MTCT, according to some social, economical and demographic variables.

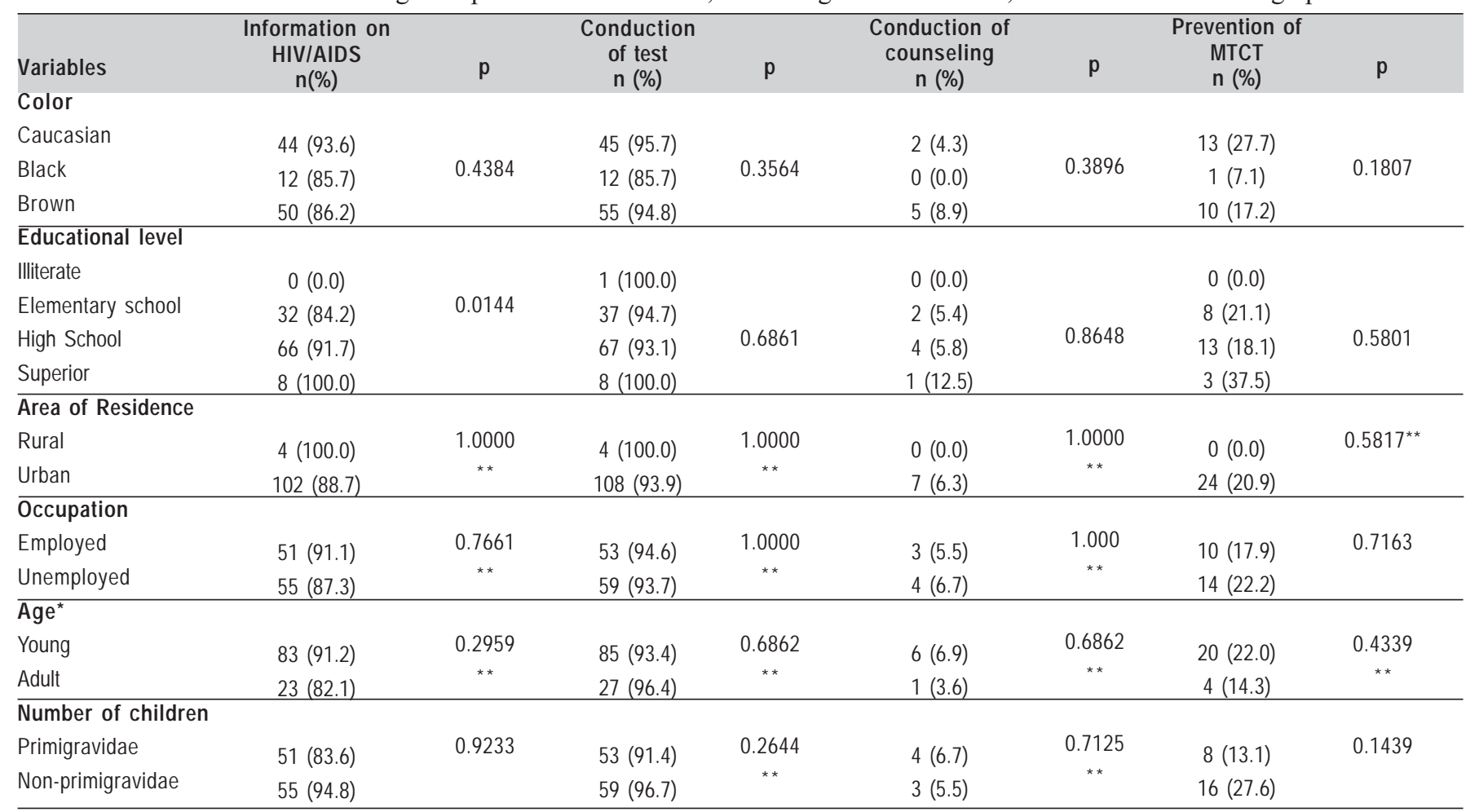

p - probability with significance level of 5\%. *Young: 14-29 years old; Adult: 30-49 years old. ** Exact Fisher test utilization 
as submission to therapeutic procedures are all consequences of the individual's educational level ${ }^{19}$. It was found that the educational level is associated with the fact that pregnant women receive information on AIDS prevention of, that is, pregnant women who have a higher educational level have shown a greater ability to assimilate information on how to prevent disease. It was also verified that, besides the lack of awareness about MTCT of HIV, most of the women in this research were not counseled, as only $5.9 \%$ answered positively when asked whether they had been counseled or not.

Thus, even if there is availability of medication for all the pregnant women and their vaccine records are acknowledged, it was noted that, in the surveyed cities, the great barrier to HIV prevention is the lack of counseling and knowledge about the subject.

In such cases, the prenatal care providers have an important role in the prevention of MTCT of HIV, for the risk of transmission to the baby is minimum when the physicians routinely offer the HIV test, conduct counseling regardless of the risk, guide those who refuse to take the test and still have proficiency to treat the ones whose outcome is positive. Therefore the importance of training the prenatal care providers is fundamental, so they may acquire more skills on prevention and treatment of MTCT of HIV ${ }^{6}$.

The pre-test counseling can be done in groups with the intent of sharing similar situations and risks among the pregnant women, creating an exchange of knowledge which can motivate them to take the HIV test and even to accomplish the prenatal care, in case the patient is HIV-positive. In this last case, the counseling must be conducted individually, because the health condition of each patient is unique and it requires specific treatment and counseling from the health care providers ${ }^{20}$. It must be stressed that the availability of information and counseling is indispensable, so the patients can be aware of the risks and means of prevention ${ }^{21}$.

In order to have positive outcome of national control and prevention of MTCT of HIV, it is necessary to implement a solid policy in the public health system, in which parents are encouraged to take HIV testing, receive prenatal routine counseling, have the availability of ARV medications, have skilled health care providers and humanized care for HIVpositive patients ${ }^{22-24}$.

Education is the basis for the prevention of HIV/AIDS contamination, and therefore, information and awareness campaigns for the entire population can collaborate with increased knowledge of the disease, and consequently, its prevention methods. However, when it comes to keeping the new educational precepts, the cultural aspect can negatively impact the expected outcome, that is, knowledge can reach the pregnant woman, but the use of preventive methods of MTCT during pregnancy relies solely on the mother ${ }^{25}$.

Access to HIV testing is critical to reduce MTCT rates, but, based on the study findings, it appears that it is not enough. Adequate prenatal care with counseling, monitoring, treatment and testing for HIV, should be implemented in early pregnancy. Thus, research aimed to evaluate the public health system should be carried out in the prenatal visits, which improve and strengthen the struggle against MTCT of HIV.

Although most pregnant women have taken the HIV test, many of them did it only once during the prenatal care and very few received counseling. This factor probably reflected the remarkable lack of knowledge concerning the prevention MTCT of HIV, even by those who reported knowing how to avoid it. In this scenario, it is suggested that the State improve management skills and train health professionals and service providers, aiming for excellence in promoting public health. Dissemination of information on this subject by more effective media campaigns is also recommendable. Given this situation, the health care models in these municipalities have to be revised in accordance with the institutional dynamics and a more humane treatment for pregnant women with HIV.

\section{Acknowledgements}

All authors acknowledge the financial support by CAPES and FAPESP in granting scientific initiative and doctoral grants.

\section{References}

1. Brazil. Ministry of Health. [Epidemiological Bulletin HIV -AIDS]. Brasília: Ministry of Health; 2014 [cited 2015 Jan 9]. Avalilable from: http:// www.aids.gov.br/sites/default/files/anexos/publicacao/2014/56677/ boletim_2014_final_pdf_15565.pdf. Portuguese

2. Brazil. Ministry of Health. [Recommendations for the Prophylaxis of Vertical Transmission of HIV and Antiretroviral Therapy in Pregnant Women: pocket handbook]. Brasília: Ministry of Health; 2010 [cited 2015 Jan 9]. Available from: http://www.aids.gov.br/sites/default/files/ consenso_gestantes_2010_vf.pdf. Portuguese

3. Ononge S, Karamagi C, Nakabiito C, Wandabwa J, Mirembe F, Rukundo $\mathrm{GZ}$, et al. Predictors of unknown HIV serostatus at the time of labor and delivery in Kampala, Uganda. Int J Gynaecol Obstet. 2014;124: 235-9.

4. Passos SC, Oliveira MIC, Gomes Júnior SC, Silva KS. HIV rapid test counseling among parturient. Rev Bras Epidemiol. 2013; 16: 278-87.

5. Birhane T, Tessema GA, Alene KA, Dadi AF. Knowledge of pregnant women on mother-to-child transmission of HIV in Meket District, Northeast Ethiopia. J Pregnancy. 2015; 2015: 960830

6. Soeiro CM, Miranda AE, Saraceni V, Lucena NO, Talhari S, Ferreira LC. Mother-to-child transmission of HIV infection in Manaus, State of Amazonas, Brazil. Rev Soc Bras Med Trop. 2011; 44: 537-41.

7. Amoran OE, Salami OF, Oluwole FA. A comparative analysis of teenagers and older pregnant women in the utilization of prevention of mother to child transmission [PMTCT] services in Western Nigeria. BMC Int Health Hum Rights. 2012; 12: 13

8. Malaju MT, Alene GD. Determinant factors of pregnant mothers' knowledge on mother to child transmission of HIV and its prevention in Gondar town, North West Ethiopia. BMC Pregnancy Childbirth. 2012; 12: 73.

9. Asefa A, Beyene H. Awareness and knowledge on timing of mother-tochild transmission of HIV among antenatal care attending women in Southern Ethiopia: a cross sectional study. Reprod Health. 2013; 10: 66

10. Byamugisha R, Tumwine JK, Ndeezi G, Karamagi CAS, Tylleskär T. Attitudes to routine HIV counselling and testing, and knowledge about prevention of mother to child transmission of HIV in eastern Uganda: a cross-sectional survey among antenatal attendees. J IntAIDS Soc. 2010; 13: 52. 
11. Falnes EF, Tylleskär T, Paoli MM, Manongi R, Engebretsen IMS. Mothers' knowledge and utilization of prevention of mother to child transmission services in northernTanzania. J Int AIDS Soc. 2010; 13: 36.

12. Soares ML, Oliveira MI, Fonseca VM, Brito AS, Silva KS. Predictors of unawareness of HIV serostatus among women submitted to the rapid HIV test at admittance for delivery. Cienc Saude Coletiva. 2013; 18: 1313-20.

13. Holla R, Maroli S, Wettasinghe D, Unnikrishnan B, Kamath S, De R, et al. Perception of HIV testing and counseling among integrated counseling and testing center clients of tertiary level hospitals. J Int Assoc Provid AIDS Care. 2015 Jan 14. pii: 2325957414567683.

14. Garbin CAS, Garbin AJI, Moimaz SAS, Rocha NB. [The HIV vertical transmission through the perception of Brazilian women]. Rev Odontol Araçatuba. 2012; 33: 41-5. Portuguese

15. Veloso VG, Bastos FI, Portela MC, Grinsztejn B, João EC, Pilotto JH, et al. HIV rapid testing as a key strategy for prevention of mother-to-child transmission in Brazil. Rev Saude Publica. 2010; 44: 803-11.

16. Kominami M, Kawata K, Ali M, Meena H, Ushijima H. Factors determing prenatal HIV testing for prevention of mother to child transmission in Dar Es Salaam, Tanzania. Pediatr Int. 2007; 49: 286-92.

17. UNAIDS. Countdown to zero: global plan towards the elimination of new infections among children by 2015 and keeping their mothers alive: 20112015. 2011 [cited 2015 Jan 9]. Available from: http: //www.unaids.org/ sites/defaultfiles/media_asset/20110609_JC2137_Global-Plan-EliminationHIV-Children_en_1.pdf.

18. Filippi V, Ronsmans C, Campbell OM, Graham WJ, Mills A, Borghi J, et al. Maternal health in poor countries: the broader context and a call for action. Lancet. 2006; 368: 1535-41.

19. Araujo ESP, Friedman RK, Camacho LAB, Derrico M, Moreira RI, Calvet GA, et al. Cascade of access to interventions to prevent HIV mother to child transmission in the metropolitan area of Rio de Janeiro, Brazil. Braz J Infect Dis. 2014; 18: 252-60.

20. Goldani MZ, Giugliani ER, Scanlon T, Rosa H, Castilhos K, Feldens L, et al. Voluntary HIV counseling and testing during prenatal care in Brazil. Rev Saude Publica. 2003; 37: 552-8.

21. United Nations Children's Found. Children orphaned by AIDS: front-line responses from eastern and southern Africa. New York: UNICEF; 1999 [cited 2015 Jan 9]. Available from: http: //www.unicef.org/publications/ files/pub_aids_en.pdf.

22. Pottie K, Medu O, Welch V, Dahal GP, Tyndall M, Rader T, et al. Effect of rapid HIV testing on HIV incidence and services in populations at high risk for HIV exposure: an equity-focused systematic review. BMJ Open. 2014; 4: e006859.

23. Passos AA, Moura ERF. Process indicators in the Program for Humanization of Prenatal Care and Childbirth in Ceará State, Brazil: analysis of a historical series (2001-2006). Cad Saúde Pública. 2008; 24: 1572-80.

24. Paintsil E, Andiman WA. Update on successes and challenges regarding mother-to-child transmission of HIV. Curr Opin Pediatr. 2009; 21: 94-101.

25. Von Linstow ML, Rosenfeldt V, Lebech AM, Storgaard M, Hornstrup T, Katzenstein TL, et al. Prevention of mother-to-child transmission of HIV in Denmark,1994-2008. HIV Med. 2010; 11: 448-56. 